\title{
OBTENÇÃO DE LEITE COM BAIXO TEOR DE LACTOSE POR PROCESSOS DE SEPARAÇÃO POR MEMBRANAS ASSOCIADOS À HIDRÓLISE ENZIMÁTICA
}

\author{
OBTAINING OF MILK WITH LOW LACTOSE PROCESS FOR SEPARATION MEMBRANES \\ BY ASSOCIATED WITH ENZYMATIC HYDROLYSIS
}

\author{
Rubens Faedo ${ }^{1}$, Vandré Barbosa Brião ${ }^{2}$, Suelen Castoldi ${ }^{3}$, Laisa Girardelli ${ }^{4}$, Adriana Milani ${ }^{5}$ \\ ${ }^{1}$ Aluno do curso de Pós-Graduação em Desenvolvimento de Novos Produtos e Gestão na Indústria de Alimentos - \\ Universidade de Passo Fundo. E-mail: rubensfaedo@yahoo.com.br \\ ${ }^{2}$ Professor do curso de Pós-Graduação em Desenvolvimento de Novos Produtos e Gestão na Indústria de Alimentos - \\ Universidade de Passo Fundo. E-mail: vandre@upf.br \\ ${ }^{3}$ Aluna do curso de Engenharia de Alimentos - Universidade de Passo Fundo. E-mail: su.castoldi@ gmail.com \\ ${ }^{4}$ Aluna do curso de Engenharia de Alimentos - Universidade de Passo Fundo. E-mail: laisagirardelli@hotmail.com \\ ${ }^{5}$ Aluna do curso de Engenharia de Alimentos - Universidade de Passo Fundo. E-mail: adrianamilani2012@gmail.com
}

\section{RESUMO}

\begin{abstract}
Muitos indivíduos deixam de consumir leite pelo fato de haver alguma restrição, normalmente, por dois motivos: intolerância à proteína ou intolerância à lactose. Esta última atinge quase a metade da população mundial. O objetivo deste trabalho foi avaliar um processo híbrido combinando ultrafiltração (UF), nanofiltração (NF) e hidrólise enzimática para a obtenção de leite pasteurizado com reduzido teor de lactose. Leite desnatado foi ultrafiltrado em unidade piloto de filtração por membranas, separando duas correntes: permeado e retido. A corrente do permeado da ultrafiltração foi coletada e armazenada sob refrigeração para posterior utilização no processo de nanofiltração. A corrente do permeado da NF foi, então, reincorporada na do retido da UF, na qual estavam presentes proteínas, gordura, sais minerais e vitaminas do leite. No produto resultante, foi realizada a hidrólise enzimática com o uso da enzima betagalactosidade. O produto final foi pasteurizado a $75^{\circ} \mathrm{C}$ por $15 \mathrm{~s}$. Análises físico-químicas e microbiológicas foram realizadas para caracterização do produto, tendo tais parâmetros sido definidos com base na legislação e em outros estudos científicos. $\mathrm{O}$ produto final apresentou-se dentro dos parâmetros exigidos pela legislação, tendo a redução de lactose chegado a $93 \%$ em relação ao teor inicial, representando uma boa alternativa para as indústrias de laticínios, agregando valor ao produto e dispondo um alimento alternativo para os consumidores com intolerância à lactose.
\end{abstract}

Palavras-chave: Separação por membranas. Lactose. Hidrólise enzimática.

\begin{abstract}
Many individuals fail to consume milk because there is some restriction, usually for two reasons: protein intolerance or lactose intolerance. The latter reaches almost half the world's population. The aim of this study was to evaluate a hybrid process combining ultrafiltration (UF), nanofiltration (NF) and enzymatic hydrolysis to obtain pasteurized milk with reduced lactose content. Skim milk was ultrafiltered in a pilot unit membrane filtration, separating two streams: penetration and retention. The current ultrafiltration permeate was collected and stored under refrigeration for later use in nanofiltration process. The NF permeate stream was then remixed with the UF retentate, which were present in the protein, fat, minerals and vitamins of milk. In the resulting product, enzymatic hydrolysis was carried out with the use of the enzyme betagalactosidade. The final product was pasteurized at $75{ }^{\circ} \mathrm{C}$ for $15 \mathrm{sec}$. Physical-chemical and microbiological analyzes were performed for characterization of the product, and such parameters have been defined based on legislation and other scientific studies. The final product was within the parameters required by the legislation, and the reduction of lactose reached $93 \%$ compared to the initial rate, representing a good alternative to dairy industries, adding value to the product and providing a food alternative for consumers with lactose intolerance.
\end{abstract}

Keywords: Membrane separation. Lactose. Enzymatic hydrolysis. 


\section{INTRODUÇÃO}

O setor lácteo exerce um importante papel para a economia brasileira, tendo, segundo Rubez (2012), encerrado o ano de 2011 com uma produção total próxima de 31 bilhões de litros, um modesto crescimento de $1 \%$ em relação ao ano de 2010. Para 2012, o volume deve subir para 32,3 bilhões de litros, um avanço de $4 \%$.

A ampliação do consumo de leite e derivados, no Brasil, enfrenta ainda diversos obstáculos, sendo o maior deles a necessidade de convencer a população de que o leite é um produto essencial à saúde e deve ser mais consumido. De acordo com a Revista Exame (2008), os brasileiros consomem, em média, 40 litros de leite líquido por ano, comparado com 68 litros de cerveja e 55 litros de refrigerante. Percebe-se que não é uma tarefa fácil a conquista de maior espaço no mercado de bebidas (Wilkinson, 2009).

O motivo para o não consumo do leite por muitos indivíduos decorre de restrições ao seu consumo, tais como intolerância à proteína ou à lactose. A má absorção ou má digestão de lactose deve-se à diminuição na capacidade de hidrolisar a lactose, o principal carboidrato do leite, resultante da hipolactasia, que significa diminuição da atividade da enzima $\beta$-galactosidade, conhecida popularmente por lactase, na mucosa do intestino delgado.

Do ponto de vista físico-químico, a lactose está presente no leite, em média 5\%, no estado molecular em solução verdadeira, com partículas de diâmetros inferiores a $1 \eta \mathrm{m}$. É formada pela junção de dois monossacarídeos, uma molécula de glicose e uma molécula de galactose, tendo o mesmo peso molecular da sacarose da qual difere, contudo, na configuração molecular, no poder edulcorante, na solubilidade e no poder redutor. A lactose é cerca de dez vezes menos solúvel que a sacarose e também apresenta um baixo poder adoçante. Isso faz da hidrólise da lactose uma possibilidade atrativa para a obtenção de um xarope mais doce contendo glicose e galactose (Longo, 2006).

A lactose é utilizada pelos mamíferos, logo depois da sua hidrólise sob a ação da lactase que corta a ligação $\beta$ 1-4. É no intestino delgado, ao nível do jejuno, que é segregada a lactase, que desdobra a lactose em glicose e galactose, fazendo que a absorção intestinal seja possível. As pessoas deficientes em lactase não têm essa capacidade, e, quando consomem leite, a lactose não é desdobrada no intestino delgado, não sendo absorvida. Dessa forma, a pressão osmótica do intestino aumenta, e uma quantidade considerável de água é retirada dos tecidos vizinhos. Então, a lactose passa para o intestino grosso, onde é fermentada por grupos microbianos produtores de gases e água, ou é hidrolisada por bactérias em ácidos orgânicos de cadeia curta. Os gases que não são absorvidos causam inchaço, e os ácidos produzidos irritam a parede intestinal e aumentam a motilidade, que combinada com a água secretada no intestino resulta em diarreia (Longo, 2006).

A lactase está presente em todos os segmentos do intestino delgado, em todos os mamíferos, com exceção dos pinípedes (foca), cujo leite não tem lactose. Também em todos os mamíferos, e na maior parte dos seres humanos, os níveis dessa enzima caem vertiginosamente após o desmame, em níveis próximos de $10 \%$ de sua atividade anterior. Essa condição leva a que algumas populações, nas quais a atividade lactásica é muito pequena, desenvolvam sintomatologia digestiva após a ingestão de leite. A lactase, ao contrário de outras dissacaridases, como sacarase e maltase, não é enzima adaptativa, ou seja, seus níveis não variam de acordo com a quantidade de carboidrato ingerido (Lopez, 2009).

A intolerância à lactose é definida como o conjunto de sintomas como dores abdominais, diarreia, flatulência, náuseas e vômitos após a ingestão da lactose. Quando sistêmicos, podem oferecer outros sintomas, conhecidos como secundários, que se caracterizam por dores de cabeça, dificuldades de concentração e redução de memória, dores musculares, arritmia cardíaca, úlceras bucais e reações alérgicas, como rinites, eczemas, sinusite e asma (Dietrich, 2011).

De acordo com Longo (2006 apud Kocián, 1988; Téo, 2002), a intolerância à lactose pode ser classificada em três grupos, que representam o modo como se manifesta. A intolerância genética, 
congênita, manifestada em recém-nascidos, é uma condição permanente, sendo uma forma de deficiência muita rara. A intolerância adquirida é aquela que se manifesta após uma inflamação ou algum dano permanente na mucosa intestinal; geralmente, apresenta-se em adultos e é muito comum, afetando cerca de $3 / 4$ da população mundial. A intolerância transitória é, usualmente, condição temporária causada por dano à mucosa intestinal. Depois que o dano é reparado, a mucosa regenera-se e passa a produzir lactase novamente, ainda que seja uma das últimas enzimas que volta a ser produzida.

A deficiência de lactose primária, também conhecida como hipolactasia adulta, lactase não persistente ou deficiência de lactase hereditária, é considerada a maior responsável pelos sintomas de má absorção de lactose, sendo a principal razão para a grande variação de atividade enzimática em diferentes populações o fato de a produção de enzima ser determinada geneticamente, de modo recessivo autossômico, por gene localizado no cromossomo dois. A produção de lactase, quando determinada geneticamente, não poderá ser induzida pela ingestão de lactose. Com base nesses estudos, verificou-se que algumas etnias como africana e asiática são mais propensas a desenvolver a hipolactasia (Dietrich, 2011).

A intolerância à lactose é uma das desordens genéticas mais comuns, atingindo mais de $46 \%$ da população mundial. No Brasil, 88 milhões de pessoas apresentam alguma dificuldade em digeri-la, pela deficiência da enzima lactase no intestino (Prozyn, 2010). Hoje, muitos países possuem uma gama de produtos com baixo teor de lactose, porém, no Brasil, esse mercado ainda tem sido pouco explorado. Com exceção do leite UHT, disposto nas versões integrais e semidesnatado, não há versões de leite desnatado e/ou pasteurizado desses produtos. Contudo, o leite desnatado contém menor teor calórico que o integral ou semidesnatado, sendo bom aliado para a saúde cardiovascular (Spadoti, 2010).

Alternativas alimentares são importantes, pois para pessoas com má absorção de lactose, normalmente, a única alternativa é abster-se dela para evitar os sintomas. Para a maioria dos indivíduos intolerantes, um copo de leite é suficiente para desencadear os sintomas, embora os que possuem alta sensibilidade possam desencadear os sintomas com baixíssimas doses de lactose, como as presentes em remédios (Dietrich, 2011).

Diante desse quadro, normalmente, recomenda-se para essas pessoas evitar o consumo de leite e seus derivados. No entanto, esses indivíduos estariam deixando de usufruir dos benefícios do alimento à saúde humana. Torna-se necessário, então, o desenvolvimento de métodos para a preparação de leite livre da lactose. O leite com baixo teor de lactose pode ser preparado por meio de sua remoção física ou de sua hidrólise enzimática, pela liberação dos seus correspondentes monossacarídeos, glicose e galactose (Cunha et al., 2007).

A hidrólise da lactose é um processo promissor para a indústria de alimentos, porque possibilita o desenvolvimento de novos produtos sem lactose em suas composições. Essa operação oferece certas vantagens tecnológicas, na medida em que diminui os riscos de cristalização nos derivados lácteos e aumenta o poder adoçante. Existem dois métodos principais para a hidrólise da lactose: o método químico e o método enzimático (Longo, 2006).

O método químico não é utilizado na indústria de alimentos, pois depende de altas temperaturas e utilização de ácidos muito fortes. Consequentemente, problemas tecnológicos são fáceis de ocorrer, como desnaturação de proteínas, alteração de cor e sabor nos alimentos.

A hidrólise pelo método enzimático é catalisada pela enzima lactase ( $\beta$-galactosidase). A vantagem desse método reside no fato de que a reação processa-se à temperatura relativamente baixa, numa faixa que pode variar de $4^{\circ} \mathrm{C}$ a $40^{\circ} \mathrm{C}$, sendo a temperatura ótima de $30^{\circ} \mathrm{C} \mathrm{a} 40^{\circ} \mathrm{C}$, permitindo uma maior economia energética, além de não se formarem produtos colaterais (Longo, 2006).

A hidrólise enzimática da lactose do leite pode seguir dois caminhos: no primeiro, o leite cru passa pelo processo de esterilização (UHT $-141^{\circ} \mathrm{C} / 5$ segundos) e, depois do resfriamento, adiciona-se a lactase, e o leite é colocado em embalagem asséptica. A hidrólise da lactose ocorre no interior da embalagem. No segundo, o leite cru passa por uma pasteurização $\left(72^{\circ} \mathrm{C} / 15\right.$ segundos), e, após o 
resfriamento, a lactase é adicionada. A hidrólise dá-se dentro de tanques de armazenamento; assim que termina esse processo, realizam-se a esterilização e o envase asséptico. No caso de necessidade de controle do grau de hidrólise da lactose, recomenda-se o uso da técnica de crioscopia (Longo, 2006).

A filtração por membranas é rotineiramente utilizada para inúmeras aplicações dentro da indústria de laticínios, tornando-se uma parte importante do processo produtivo. O processo de separação em baixas temperaturas, sem mudança de fase, faz da filtração por membranas, em muitas aplicações, uma solução muito mais econômica que métodos convencionais, tais como filtração a vácuo ou filtros-prensas (GEA, 2012).

Dentre as alternativas da filtração por membranas, destaca-se a nanofiltração, que é um processo de filtração entre ultrafiltração e osmose reversa que proporciona separações altamente específicas de componentes com baixo peso molecular, tais como açúcares de minerais dissolvidos e sais (GEA, 2012).

De acordo com Tondello (2011 apud Eckenfelder, 1989), o processo de separação por membranas (SPM) é baseado em mecanismos físicos, não envolvendo processos químicos, biológicos ou trocas térmicas. Refere-se apenas à separação dos componentes de uma mistura pela rejeição daqueles que não possuem tamanho para atravessar os poros da membrana, e a eficiência desse tipo de filtração depende inteiramente da diferença de tamanho entre o poro e a partícula a ser removida.

Uma membrana é uma fase permeável ou semipermeável, frequentemente, um fino polímero sólido que restringe o movimento de certas espécies. Essa fase é, essencialmente, uma barreira entre o fluxo de alimento para separação e um fluxo de produto e, assim como em todas as separações, gera um produto diminuído de certos componentes e um segundo produto concentrado desses componentes (Scott; Hughes, 1996).

O transporte das espécies através da membrana surge como uma situação de desequilíbrio, e a migração dos componentes ocorre da fase de maior potencial para a fase de menor potencial. Essa diferença surge como o resultado da diferença de pressão $(\Delta \mathrm{P})$, concentração $(\Delta \mathrm{C})$, temperatura $(\Delta \mathrm{T})$ ou potencial elétrico $(\Delta \mathrm{E})$. A separação é possível devido à propriedade da membrana de transportar um componente da mistura na alimentação mais rapidamente que o(s) outro(s) componente(s). No entanto, normalmente, a membrana não é uma barreira semipermeável perfeita (ou ideal) (Mulder, 1991).

Segundo Scott e Hughes (1996), a morfologia da membrana e a natureza do material que constitui são algumas das características que definem o tipo de aplicação e a eficiência da separação. Há muitos processos com membranas, baseados em diferentes princípios ou mecanismos de separação, que fracionam espécies de distintos tamanhos que variam desde partículas até mesmo em nível molecular. A força motriz que rege o movimento depende das características da membrana, e, em geral, são aplicados gradientes de pressão, concentração, temperatura ou potencial elétrico para gerar o movimento das espécies químicas envolvidas através da membrana (Mulder, 1991).

Os processos de separação por membranas cuja força motriz é o gradiente de pressão têm uma forte analogia com a filtração convencional, em que a retenção por tamanho é o princípio básico de fracionamento das diferentes espécies químicas presentes. A microfiltração (MF), ultrafiltração (UF), nanofiltração (NF) e osmose inversa (OI) são exemplos de processos que utilizam o gradiente de pressão como força motriz (Mulder, 1991).

Deve-se salientar que as separações por MF, UF, NF e OI utilizam a pressão como força motriz, enquanto, na diálise, o processo de transporte de constituintes ocorre através de uma membrana semipermeável em que a força motriz resultante é a diferença de concentração. A passagem de íons e substâncias de baixos pesos moleculares ocorre ao mesmo tempo em que se dá a rejeição de solutos e coloides com altos pesos moleculares (Mancuso; Santos, 2003).

Dado o contexto, soluções técnicas devem ser estudadas para que os consumidores com intolerância à lactose tenham alguma opção de consumo do leite sem abrir mão desse alimento com grande importância nutricional. Por outro lado, com margens lucrativas cada vez menores no mercado de commodities, a competitividade e a sobrevivência dos laticínios brasileiros estão ligadas ao 
desenvolvimento de novos produtos de maior valor agregado. A filtração por membranas associada à hidrólise enzimática passa a ser uma importante alternativa para obter-se um leite livre ou com teor muito baixo de lactose. Diante disso, objetivou-se avaliar um processo híbrido combinando ultrafiltração, nanofiltração e hidrólise enzimática para a obtenção de leite pasteurizado com reduzido teor de lactose.

\section{MATERIAL E MÉTODOS}

\subsection{Matérias-primas e reagentes}

O leite foi doado pela empresa Laticínios Bom Gosto S/A. A enzima lactase utilizada foi de origem microbiana, obtida por meio da fermentação de cepa selecionada e específica da levedura Kluyveromyces lactis, cedida pela empresa Prozyn.

\subsection{Processamento do leite}

O processo para produção do leite com teor reduzido de lactose consiste nas etapas ilustradas no fluxograma da Figura 1, baseado na publicação de patente n ${ }^{\circ}$ WO 03/094623 A1 (Tossavainen; Sahlstein, 2003).

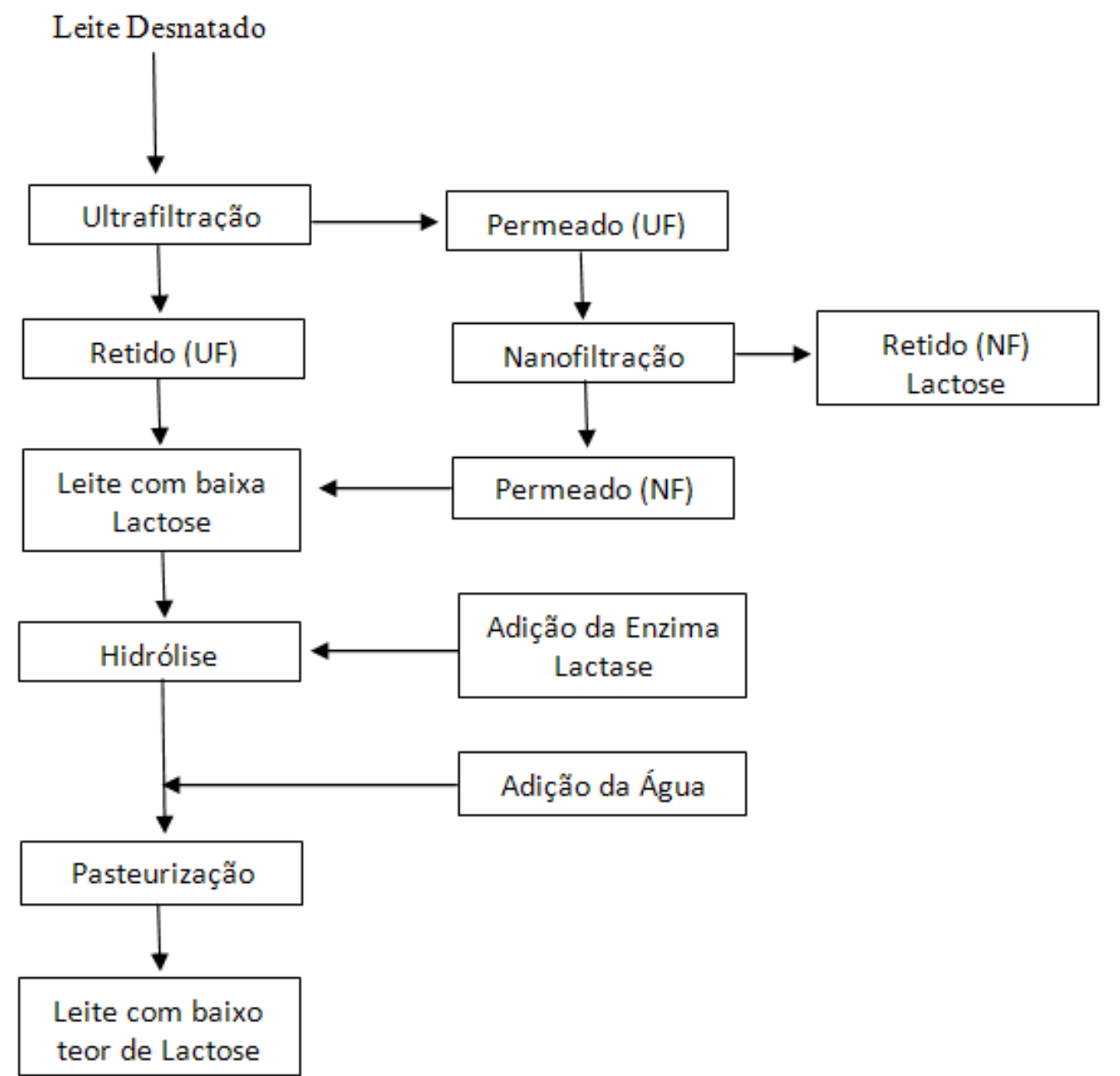

Figura 1: Fluxograma para processo do leite desnatado com baixo teor de lactose. 
Os testes de filtração no sistema de separação por membranas foram realizados sob condições controladas. A Figura 2 apresenta um diagrama do equipamento.

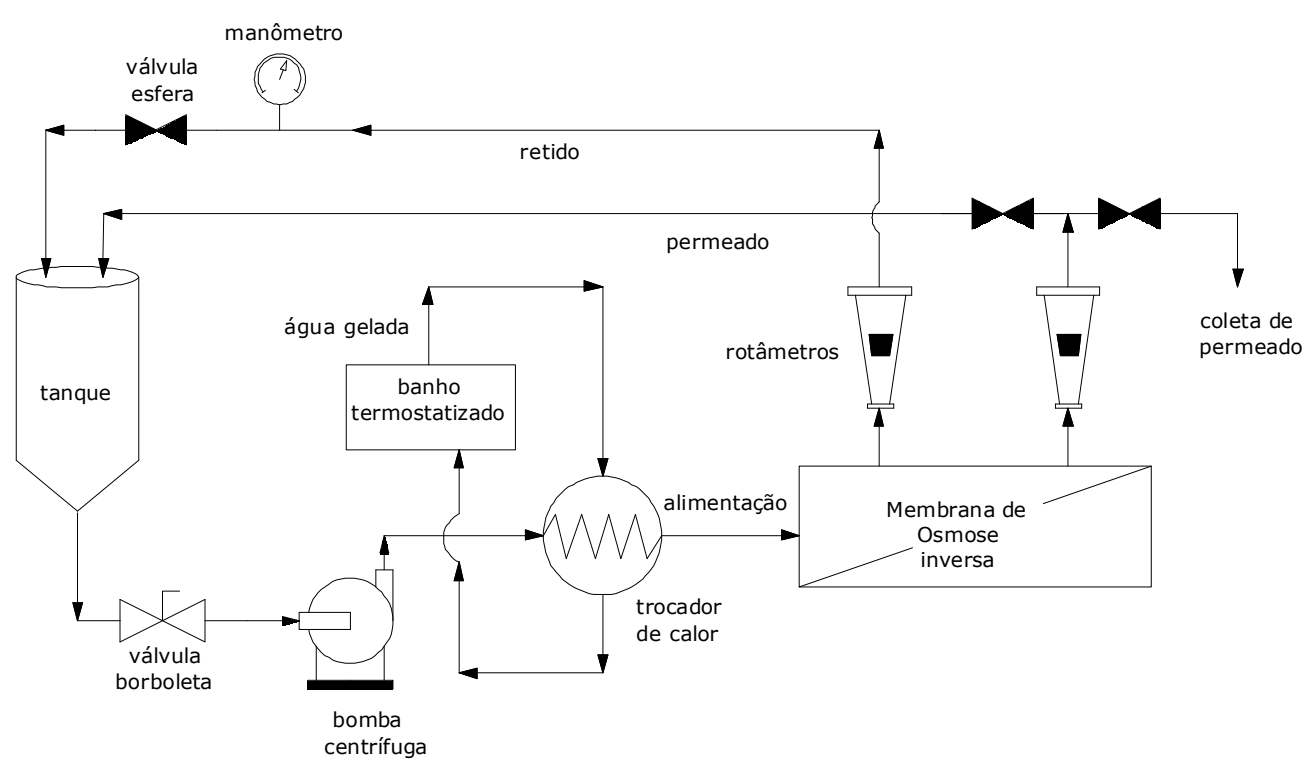

Figura 2: Diagrama do equipamento de separação por membranas

O leite desnatado foi alimentado no tanque de aço inoxidável; em seguida, foi impulsionado por uma bomba centrífuga multiestágios por meio da carcaça onde é instalada a membrana de ultrafiltração, separando duas correntes: permeado e retido. A corrente do permeado da ultrafiltração (UF) foi coletada e armazenada sob refrigeração para posterior utilização no processo de nanofiltração (NF), o qual ocorre pelo mesmo princípio do processo de ultrafiltração, porém com uma membrana com menor diâmetro de poro. A maior parte da lactose, teoricamente, ficou contida na corrente do retido na NF. A corrente do permeado da NF, então, foi reincorporada na corrente retido da UF, na qual estarão presentes as proteínas, gordura (caso houver, em pequena quantidade, por se tratar de leite desnatado), sais minerais e vitaminas do leite.

O processo foi realizado durante cinco minutos, e, ao final, foram coletadas amostras de permeado e retido para a sua caracterização físico-química. Ao longo do tempo, registrou-se o fluxo permeado em cada condição experimental testada. A Tabela 1 apresenta as condições de fluxo, temperatura, pressão e frequência do processo, no início e no final, para cada utilização de membrana.

Tabela 1: Condições do processo utilizado para cada membrana

\begin{tabular}{lcccc}
\hline & \multicolumn{2}{c}{ Membrana (UF) } & \multicolumn{2}{c}{ Membrana (NF) } \\
& Início & Final & Início & Final \\
\hline Fluxo retido $(\mathrm{L} / \mathrm{h})$ & 5000 & 4600 & 5000 & 5000 \\
Fluxo permeado $(\mathrm{L} / \mathrm{h})$ & 115 & 90 & 440 & 280 \\
Temperatura $\left({ }^{\circ} \mathrm{C}\right)$ & 25 & 28 & 25 & 26 \\
Pressão $($ bar) & 3,5 & 3,5 & 15 & 15 \\
Frequência $(\mathrm{Hz})$ & 40,26 & 40,26 & 55,83 & 55,29 \\
\hline
\end{tabular}

Após cada experimento, foi realizada uma limpeza química em todo o sistema, dividida em duas etapas: limpeza alcalina e limpeza ácida. A solução alcalina foi preparada com água e ajuste de pH 11 com adição de $\mathrm{NaOH}$. A solução ácida foi preparada com permeado e adição de ácido nítrico até que o $\mathrm{pH}$ fosse ajustado a 2 . O procedimento de limpeza teve início com um enxágue com $50 \mathrm{~L}$ de permeado. Após, foram preparados $50 \mathrm{~L}$ de solução alcalina no tanque de alimentação e recirculados por 45 min. Realizou-se um novo enxágue com permeado e, então, foi realizada a recirculação com a 
solução alcalina. Após, a membrana foi enxaguada várias vezes com permeado até que se chegou a um pH neutro (entre 6,5 e 7,5) e o fluxo de permeado reestabeleceu-se.

A adição da enzima lactase foi realizada em um tanque de aço inoxidável disposto de agitador, onde foi realizada a hidrólise enzimática, adicionando-se $80 \mathrm{~g} / 100 \mathrm{~L}$ de leite da enzima betagalactosidade, mantendo-se por 15 horas a uma temperatura de $6^{\circ} \mathrm{C}$, conforme especificado pelo fornecedor da enzima. A seguir, adicionou-se água para que o produto ficasse com o teor de sólidos totais do leite desnatado. Por fim, realizou-se a pasteurização do leite desnatado com baixo teor de lactose a $75^{\circ} \mathrm{C}$ por 15 segundos.

\subsubsection{Análises de caracterização físico-química e microbiológica das amostras}

As amostras do leite desnatado, permeado e retido foram analisadas nos parâmetros que definem suas características, tendo sido alguns padrões selecionados com base na Instrução Normativa 62/2011 do Ministério da Agricultura Pecuária e Abastecimento (Brasil, 2011), que é o regulamento técnico de identidade e qualidade do leite pasteurizado. Outros critérios de análise foram baseados em estudos científicos. As análises físico-químicas e microbiológicas foram realizadas em duplicata, utilizando metodologias oficiais.

A quantificação de gordura deu-se pelo Método C: butirométrico para leite fluido, segundo Brasil (2006). A quantificação de proteína foi obtida por meio do método de Lowry (1951). Já a concentração de lactose foi obtida com o método do ácido dinitrossalicílico (DNS), segundo Miller (1959). O potencial hidrogeniônico $(\mathrm{pH})$ foi determinado pelo método eletrométrico, usando o potenciômetro, seguindo a metodologia de análise baseada nos procedimentos da APHA (1995). Os sólidos solúveis, por sua vez, foram determinados utilizando refratômetro digital, marca ATAGO, modelo PAL-03.

Os ensaios microbiológicos foram analisados seguindo os parâmetros Contagem Padrão em Placas, Coliformes a $30-35^{\circ} \mathrm{C}$, Coliformes a $45^{\circ} \mathrm{C}$, Staphilococcus Aureus e Salmonella spp. de acordo com o método Petrifilm (Lanara, 2003).

\section{RESULTADOS E DISCUSSÃO}

\subsection{Caracterização do leite com baixo teor de lactose}

A Figura 3 ilustra, da esquerda para a direta, a alimentação à corrente de permeado e à corrente de retido, após o processo de ultrafiltração (UF).

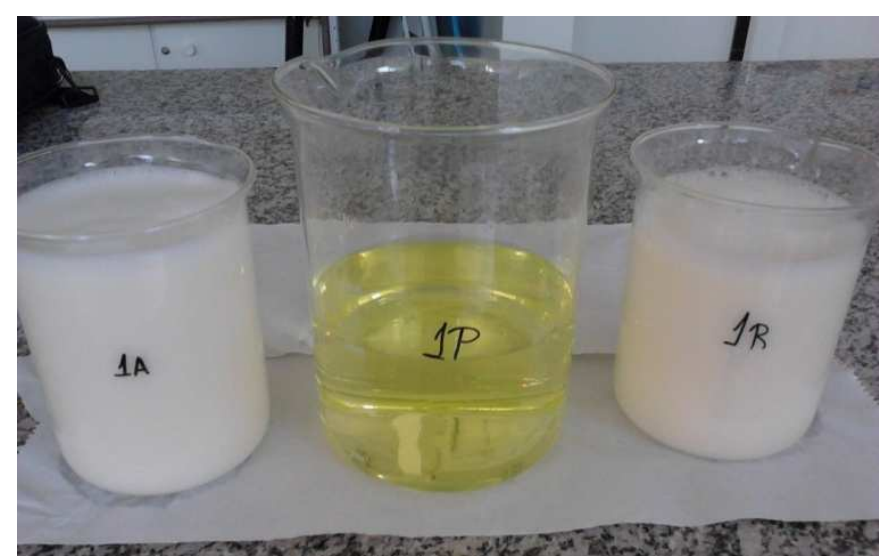

Figura 3: Foto dos produtos após o processo de ultrafiltração 
A caracterização do leite com baixo teor de lactose está apresentada na Tabela 2. Nela, encontram-se o resultado de todas as correntes de permeado e retido da UF e NF, a alimentação e o produto final após a passagem pelo processo de filtração por membranas e hidrólise enzimática.

Tabela 2: Caracterização de todas as correntes, alimentação e produto final do leite com baixo teor de lactose

\begin{tabular}{|c|c|c|c|c|c|}
\hline & $\begin{array}{c}\text { Gordura } \\
(\%)\end{array}$ & $\begin{array}{l}\text { Proteína } \\
(\mathrm{g} / 100 \mathrm{~mL})\end{array}$ & $\begin{array}{c}\text { Lactose } \\
(\mathrm{g} / 100 \mathrm{~mL})\end{array}$ & pH & ${ }^{\circ}$ Brix \\
\hline $\begin{array}{l}\text { Leite } \\
\text { (alimentação) }\end{array}$ & $0,15 \pm 0,00$ & $4,16 \pm 0,10$ & $5,86 \pm 0,00$ & $6,72 \pm 0,01$ & $8,5 \pm 0,0$ \\
\hline $\begin{array}{l}\text { Permeado } \\
\text { UF }\end{array}$ & $0,0 \pm 0,0$ & $1,04 \pm 0,33$ & $7,55 \pm 0,16$ & $6,70 \pm 0,04$ & $5,2 \pm 0,0$ \\
\hline Retido UF & $0,65 \pm 0,00$ & $13,07 \pm 0,12$ & $8,40 \pm 0,08$ & $6,75 \pm 0,01$ & $\begin{array}{c}17,3 \pm \\
0,0\end{array}$ \\
\hline $\begin{array}{l}\text { Permeado } \\
\text { NF }\end{array}$ & $0,0 \pm 0,0$ & $0,65 \pm 0,09$ & $2,00 \pm 0,00$ & $6,70 \pm 0,04$ & $0,4 \pm 0,0$ \\
\hline Retido NF & $0,0 \pm 0,0$ & $2,79 \pm 0,21$ & $14,03 \pm 0,30$ & $6,69 \pm 0,01$ & $6,7 \pm 0,0$ \\
\hline Produto final & $0,25 \pm 0,00$ & $8,63 \pm 0,08$ & $0,39 \pm 0,01$ & $6,64 \pm 0,01$ & $8,4 \pm 0,0$ \\
\hline
\end{tabular}

De acordo com a Instrução Normativa 62 (Brasil, 2011), o leite pasteurizado desnatado deve apresentar, entre outros requisitos físico-químicos, teor de gordura máximo de $0,5 \mathrm{~g} / 100 \mathrm{~g}$, critério da legislação atendido pelo produto obtido. O leite desnatado utilizado para realização do experimento, antes do procedimento de ultrafiltração, apresentava teor de gordura de 0,15\%. Como esse processo promove a remoção física da gordura do leite, a corrente do permeado apresentou ausência de gordura, tendo essa ficado concentrada na corrente do retido com $0,65 \%$. O produto final resultou em 0,25\% de gordura, pois parte da corrente do retido da UF foi utilizada para reincorporar os sólidos na corrente do permeado da NF. Com esse resultado, o produto fica dentro da faixa para leite desnatado.

Em relação aos valores de $\mathrm{pH}$, proteínas, lactose e brix, a legislação não determina quais as faixas de valores adequados a esses parâmetros para o leite pasteurizado desnatado. Porém, em revisão sobre leite pasteurizado lactose-hidrolisado associado ao processo de separação por membranas (Spadoti et al., 2010), os dados de pH são semelhantes ao obtido neste estudo, ficando próximos a 6,72. Hosino et al. (2012), em estudo de um produto semelhante cuja vida útil determinaram, obtiveram resultados de $\mathrm{pH}$ em faixas de 6,72 (1 dia) até 6,66 (40 dias), mantendo-o em temperatura de $5^{\circ} \mathrm{C}$.

Os resultados de proteínas para o produto final ficaram acima dos encontrados por Tossavainen e Sahlstein (2003), 3,35\%, e por Spadoti et al. (2010), 2,94\%. Nesse caso, é possível observar que a maior parte das proteínas ficou armazenada na corrente de retido da UF 13,07\%. O fato de essa ter sido utilizada para reincorporar a corrente do permeado da NF justifica o teor alto de proteínas, obtendo $8,63 \%$ no produto final. Esse resultado é mais do que o dobro da quantidade de proteínas do produto utilizado na alimentação, sendo um fator positivo para a obtenção de um alimento com alto teor protéico e associado a um baixo teor de gordura, podendo auxiliar no ganho de massa muscular e sendo bom aliado para a saúde cardiovascular.

Quanto à lactose, o leite desnatado utilizado nesta pesquisa possuía um teor inicial de lactose de 5,86\%. O leite elaborado pelo processo de separação por membranas associado à hidrólise enzimática apresentou 0,39\% de lactose, com redução de 93,34\%, superior à observada em leites com baixo teor de lactose encontrados nos mercados (90\%). Atualmente, a legislação brasileira não dispõe de um regulamento específico para leite com baixo teor de lactose; contudo, segundo a legislação aplicada para esse tipo de produto, a Portaria $n^{\circ} 29$ de 1998 do Ministério da Saúde, alimentos 
especialmente formulados para atender portadores de intolerância à ingestão de dissacarídeos como a lactose podem conter no máximo $0,5 \mathrm{~g}$ do nutriente por $100 \mathrm{~g}$ ou $100 \mathrm{~mL}$ do produto final.

A obtenção de leite com baixo teor de lactose, utilizando um processo combinado de separação por membranas e hidrólise enzimática, é de grande importância. Para Harju et al. (2012), quando se utiliza um processo isolado, as vantagens são menores. Em trabalhos que utilizaram somente hidrólise enzimática, devido aos elevados tempos em contato necessários para realização da hidrólise e pela temperatura ótima da atuação da enzima $\left(35-45^{\circ} \mathrm{C}\right)$, observou-se crescimento microbiano. Outros aspectos negativos em relação à hidrólise enzimática são doçura excessiva e a ocorrência da reação de Maillard, que é facilitada devido à quebra da lactose em açúcares redutores (glicose e galactose), mais reativos que a própria lactose. Segundo Harju et al. (2012), realizando processos combinados, evita-se que o produto final fique com diferente aspecto sensorial em comparação ao leite com teor de lactose original, pois, quando é retirada somente a lactose, pelo uso de membranas, por exemplo, perde-se o gosto levemente adocicado do produto.

De acordo com Harju et al. (2012), a empresa finlandesa Valio Ltda. desenvolveu e patenteou diversas técnicas para leites e derivados com baixo teor de lactose, contando, hoje, com mais de 200 produtos diferentes no seu mix com a marca HYLA, utilizando a maior parte desses produtos processos de combinações físicas e enzimáticas.

A análise de sólidos solúveis totais ( ${ }^{\circ}$ Brix) foi útil para determinar que a quantidade inicial presente de sólidos e do produto final fossem semelhantes. Como se trata de uma análise simples e rápida, esta serviu para demonstrar as concentrações de sólidos ao longo do processo. Com isso, é possível observar que, após o processo de ultrafiltração na corrente do permeado, obteve-se $5,2{ }^{\circ}$ Brix, sendo esses sólidos compostos teoricamente de proteínas, açúcares (lactose), sais minerais e vitaminas. Logo, a corrente do retido (UF) obteve-se $17,3{ }^{\circ}$ Brix, em cuja composição predominam proteínas, gordura e uma parcela de açúcares. Para o processo de nanofiltração, a corrente de permeado resultou $0,4^{\circ}$ Brix e $6,7^{\circ}$ Brix de retido, sendo essa a maior parte composta de lactose.

A avaliação microbiológica demonstrou que o uso combinado dos processos de separação por membranas associados à hidrólise enzimática, para obtenção de um leite com baixo teor de lactose, atende aos parâmetros exigidos pela legislação para leite pasteurizado, resultando em um produto com boa qualidade higiênico-sanitária, conforme está apresentado na Tabela 3.

Tabela 3: Caracterização microbiológica do leite com baixo teor de lactose

\begin{tabular}{ccccc}
\hline $\begin{array}{c}\text { Contagem } \\
\text { padrão em } \\
\text { placas }\end{array}$ & $\begin{array}{c}\text { Coliformes 30- } \\
35^{\circ} \mathrm{C} \\
(\mathrm{UFC} / \mathrm{mL})\end{array}$ & $\begin{array}{c}\text { Coliformes 45 } \\
(\mathrm{NMP} / \mathrm{mL})\end{array}$ & $\begin{array}{c}\text { Staphilococcus } \\
\text { aureos }\end{array}$ & $\begin{array}{c}\text { Salmonella } \\
\text { spp/ 25mL }\end{array}$ \\
\hline $8 \times 10^{3}$ & Ausente & Ausente & Ausente & Ausente \\
\hline
\end{tabular}

\section{CONCLUSÃO}

O leite pasteurizado com baixo teor de lactose por processos de separação de membranas associados à hidrólise enzimática apresentou uma redução de $93 \%$ do teor de lactose original. Isso faz que a produção desse tipo de produto seja uma boa alternativa para as indústrias de laticínios, agregando valor ao produto e dispondo para os consumidores um alimento alternativo para quem possui intolerância à lactose. 


\section{REFERÊNCIAS}

AMERICAN PUBLIC HEALTH ASSOCIATION (APHA). Standard methods for the examination of water and wastewater. 19. ed. Washington: APHA, 1995.

BEHMER, M. L. A. Tecnologia do leite: produção, industrialização e análise, 9. ed. São Paulo: Nobel, 1979. 322p.

BRASIL. Ministério da Agricultura Pecuária e Abastecimento. In: $n^{\circ}$ 68. Métodos analíticos oficiais físico-químicos, para controle de leite e produtos lácteos. Diário Oficial da União, Brasília, 14 dez. 2006.

In: $\mathrm{n}^{\circ}$ 62. Regulamento técnico de identidade e qualidade do leite pasteurizado. Diário Oficial da União, Brasília, 30 dez. 2011.

Ministério da Saúde. Resolução RDC $\mathrm{n}^{\circ}$ 348. Utilização de enzimas na indústria de alimentos. Diário Oficial da União, Brasília, 02 dez. 2003.

Secretaria Nacional de Defesa Agropecuária. Laboratório Nacional de Referência Animal (Lanara). Métodos analíticos oficiais para controle de produtos de origem animal e seus ingredientes. Brasília - DF, 2003.

. Secretaria de Vigilância Sanitária. Ministério da Saúde. Portaria no. 29. Regulamento técnico para fixação de identidade e qualidade de alimentos para fins especiais. Diário Oficial da União, Brasília, 13 jan. 1998.

CUNHA, L. R. et al. Desenvolvimento e avaliação de embalagem ativa com incorporação de lactase. Ciência e Tecnologia de Alimentos, Campinas, v. 27, p. 23-26, 2007.

DIETRICH, J. M. Intolerância a lactose, um nicho de mercado a ser explorado. Revista Leite 2011. Disponível em:

<http://www.globalfood.com.br/site/site/arquivos/Intolerancia\%20a\%20lactose\%20por\%20Jaime\%20 Marcos\%20Dietrich.pdf >. Acesso em: 26 ago. 2012.

GEA FILTRATION. Filtração por membranas. Catálogo de exposição, 2006. Disponível em: $<$ http://www.geafiltration.com/filtration_library/membrane_filtration_Portuguese.pdf $>$. Acesso em: 23 set. 2012.

HABERT, A. C.; BORGES, C. P.; NOBREGA, R. Processo de separação por membranas. Escola Piloto em Engenharia Química. Rio de Janeiro: E-papers, 2006.

HARJU, M.; KALLIOINEN, H.; TOSSAVAINEM, O. Lactose hydrolysis and other conversions in dairy products: Technological aspects. International Dairy Jornal, v. 22, p. 104-109, 2012

HOSHINO, L. K. O. et al. Estudo da hidrólise na obtenção de leite lactose hidrolisado microfiltrado e avaliação de parâmetros físico-químicos para determinação da sua vida útil. In: CONGRESSO INTERINSTITUCIONAL DE INICIAÇÃO CIENTÍFICA, 3, 2009, Campinas. Anais eletrônicos. Campinas: IAC, 2009. Disponível em: 
<http://www.iac. sp.gov.br/areadoinstituto/pibic/anais/2009/Artigos/RE0901015.pdf>. Acesso em: 26 Jan. 2012.

LONGO, G. Influência da adição de lactase na produção de iogurte. 2006. Dissertação (Mestrado em Tecnologia de Alimentos) - Setor de Tecnologia, Universidade Federal do Paraná, Curitiba, 2006.

LOPEZ, F. A. Os dilemas da intolerância à lactose. Ades atualiza, ano 1, n. 2, jan./fev./mar. 2009.

LÖWRY, O. H. et al. Protein measurement with the foline reagent. J. Biol. Chem., p. 193-265, 1951.

MANCUSO, P. C. S.; SANTOS, H. F. Reuso de água. Barueri: Manole, 2003.

MILLER, G. L. Use of dinitrosalicylic acid reagent for determination of reducing sugar. Anal. Chem., v. 31, p. 426-428, 1959.

MULDER, M. Basic principles of membrane technology. Dordrecht: Kluwer Academic Publisher, 1991.

PROZYN. Produtos com baixa lactose. Informação técnica. 2010.

RUBEZ, J. Produção de leite deve crescer 4\% em 2012. Revista Globo Rural On-line 2012. Disponível em:

<http://revistagloborural.globo.com/Revista/Common/0,,EMI294991-18077,00-

PRODUCAO+DE+LEITE+DEVE+CRESCER+EM.html>. Acesso em: 06 set. 2012

SCOTT, K.; HUGHES, R. Industrial membrane separation technology. London: Blackie Academic \& Professional, 1996. 305 p.

SPADOTI, L. M. et al. Vida útil de leite desnatado pasteurizado lactose-hidrolisado microfiltrado. UNOPAR Científica, Ciências Biológicas e da Saúde, Londrina, v. 12, p. 61-65, 2010.

TONDELLO, T. F. Recuperação por osmose inversa de águas residuais geradas na produção de leite condensado. 2011. Monografia (Graduação em Engenharia Ambiental) - Universidade de Passo Fundo, Passo Fundo, 2011.

TOSSAVAINEN, O.; SAHLSTEIN, J. Process for producing a lactose-free milk product. World Intellectual Property Organization, Switzerland, 2003. Patent number WO 03/094623.

WILKINSON, J. (Coord.). Perspectivas do investimento no agronegócio. Rio de Janeiro: UFRJ, Instituto de Economia, 2008/2009. Relatório integrante da pesquisa "Perspectivas do Investimento no Brasil", em parceria com o Instituto de Economia da UNICAMP, financiada pelo BNDES. Disponível em: 〈http://www.projetopib.org/?p=documentos>. Acesso em: 23 set. 2012. 